\title{
POLÍTICAS DO DESPERDÍCIO E ASSIMETRIA ENTRE PÚBLICO E PRIVADO NA INDÚSTRIA AUTOMOBILÍSTICA*
}

\section{Glauco Arbix}

Nos anos de 1990, uma intensa e agressiva disputa por investimentos estrangeiros tomou conta do setor automotivo brasileiro. Estados e municípios articularam-se, patrocinados pelo governo central, agências federais, fundos estaduais e bancos oficiais - como o BNDES - e ofereceram a devolução do imposto recolhido (ou o devido) às próprias empresas, através das mais variadas formas de financiamento, sempre a taxas mais generosas que as do mercado.

A guerra foi chamada fiscal por estar baseada no jogo com a receita e a arrecadação futura do ICMS. Envolve, porém, diferentes taxas e financiamento para capital de giro e infra-estrutura, incluin-

* À Fapesp e ao CNPq meus agradecimentos. Gostaria também de agradecer as sugestões recebidas do corpo de pareceristas da RBCS. Versão preliminar deste texto foi apresentada no Seminário Internacional "A Indústria Automobilística nas Américas", IUPERJ-UCAM, Rio de Janeiro, março de 2001. do terraplanagem, vias de acesso, terminais portuários, ferroviários e rodoviários, assim como malhas de comunicação e mesmo a diminuição das tarifas de energia elétrica. Nos municípios, taxas, IPTU e ISS foram oferecidos por até trinta anos.

Os mecanismos utilizados para atrair esses novos investimentos foram crescendo em sofisticação. Apesar de alguns constrangimentos sedimentados pela nova lei de Responsabilidade Fiscal e por algumas das propostas de reforma fiscal em discussão, dificilmente serão completamente extintos sem um novo entendimento político entre os Estados da federação. Exatamente pelas dificuldades que esse processo envolve, parece-nos que, a médio prazo, não há solução capaz de impedir que um governo estadual procure melhorar sua economia e bem-estar às custas de outras regiões. Exatamente por isso, a questão de fundo atualizada pela guerra fiscal possui uma dimensão nacional e política, pois toca, de fato, nos alicer- 
ces de nossa sociedade, na medida em que sugere a busca de um novo equilíbrio entre cooperação e conflito na federação brasileira.

Enquanto isso, a discussão sobre a eficácia dessa política de aguda competição interestadual entendida como instrumento de modernização industrial, capacitação regional e de diminuição de desigualdades econômicas, permanece uma tarefa básica a ser realizada. Detectamos ao longo da nossa pesquisa uma série de impasses, obstáculos e problemas que tem nos levado a questionar a competição entre Estados, pelo menos no formato atual em que está configurada.

O presente texto buscará discutir: 1) as razões da descentralização da indústria de auto veículos; 2) a natureza da competição interterritorial; 3) alguns de seus custos; 4) o despreparo dos governos para enfrentar a negociação com as grandes corporações; e 5) os primeiros resultados negativos e sugestões de mudança.

Nossa hipótese central é que, embora muitos empreendimentos resultantes da atual onda de investimentos ainda não tenham amadurecido, essa disputa representa um enorme desperdício de recursos públicos, tanto para os governos diretamente envolvidos, quanto para o país como um todo. As regras do jogo, as armas e o território da guerra fiscal favorecem, em primeira instância, as grandes montadoras que, de fato, comandam as negociações. O setor público, fragilizado e despreparado, teve seu espaço reduzido, ao mesmo tempo em que o espaço privado foi sendo gradativamente ampliado.

A ausência de nitidez nas novas estratégias de industrialização e a precariedade institucional capaz de desenhar novos caminhos para o desenvolvimento nacional parece estar na raiz de mais um jogo de ilusões na história recente do Brasil.

\section{A terceira onda}

O Brasil dos anos de 1990 procurou excluir das diretrizes públicas a idéia de política industrial. Em vão. A ausência de instituições e estratégias para elaborar e coordenar os novos processos industriais deixou o projeto de desmontagem da antiga estrutura desenvolvimentista no meio do caminho, só que agora, com maior dependência das multinacionais, sem qualquer ênfase no capital doméstico e centralmente descoordenado em suas linhas estratégicas.

O setor automotivo foi um dos poucos que recebeu especial atenção do governo federal. Talvez por isso continue como um dos mais bem protegidos em sua estrutura produtiva e em seu mercado. Uma proteção assimétrica, sem dúvida, uma vez que as montadoras continuam sendo as grandes beneficiárias do novo protecionismo governamental, em detrimento do setor de autopeças, cuja regulamentação consagrada pelo Novo Regime Automotivo (NRA) ${ }^{1}$ privilegiou as corporações internacionais, drenando força da indústria doméstica, construída ao longo dos últimos quarenta anos. Para não falar na dimensão trabalho e trabalhadores, neste caso, implicitamente ignorada pelas políticas do novo regime (Posthuma, 1997; Veiga, 1999; Cardoso, 2000).

O NRA foi bem-sucedido na atração de novos investimentos e empresas, como podemos ver pelas tabelas e mapa a seguir. No plano federal, porém, as tentativas de coordenação dessa nova migração de montadoras mostrou inconsistência e inconstância, com impactos visíveis no sub-aproveitamento do novo potencial existente.

No plano federal, no final do primeiro mandato do presidente Fernando Henrique Cardoso, a tentativa de criação de um super-ministério, o do Desenvolvimento, revelou-se subordinada e constrangida pelas diretrizes emanadas do Ministério da Fazenda.

Regionalmente, Estados e municípios passaram a desenvolver mais intensamente projetos de modernização produtiva buscando a melhoria do perfil econômico de suas regiões. Para isso, contribuíram tanto a maior autonomia fiscal-tributária concedida pela Constituinte de 1998 aos governos subnacionais quanto a descentralização de responsabilidades pela elaboração e implementação de políticas de desenvolvimento, resultante das novas diretrizes assumidas pelo governo federal, sinalizando um distanciamento do velho estilo prepotente e centralizador do Estado brasileiro. No entanto, desprovidos de canais institucionalizados de comunicação com o setor produtivo, sem contar com corpos técnicos aptos a desenvol- 
ver o planejamento e de programar escolhas de longo prazo, governadores e prefeitos passaram a recorrer a instrumentos imediatamente disponíveis, que tinham a vantagem de produzir dividendos no curto e médio prazo. Muitas vezes, o lento trabalho de reforma, reconstrução e criação de instituições regionais, apropriadas para estimular, monitorar, regular e, principalmente, legitimar para utilizar as expressões de Polanyi - cedeu lugar à busca da diminuição das defasagens industriais a partir de um processo de canibalização Estados e regiões da federação.

Despreparados regionalmente e sem parâmetros nacionais, Estados e municípios politizaram a competição por novos investimentos, em especial os estrangeiros, deflagrando uma disputa interterritorial (Rodríguez-Pose e Arbix, 2001). Os Estados que mais participaram dessa guerra tiveram relativo êxito na atração de novos investimentos, desconcentrando a produção de autoveículos, anteriormente localizada no Estado de São Paulo, Minas Gerais e, em menor escala, no Paraná. O novo mapa dessa indústria foi completamente alterado (Figura 1)
Figura 1

Distribuição Territorial dos Investimentos

Credenciados no Novo Regime Automotivo (1996-2001), por Estado

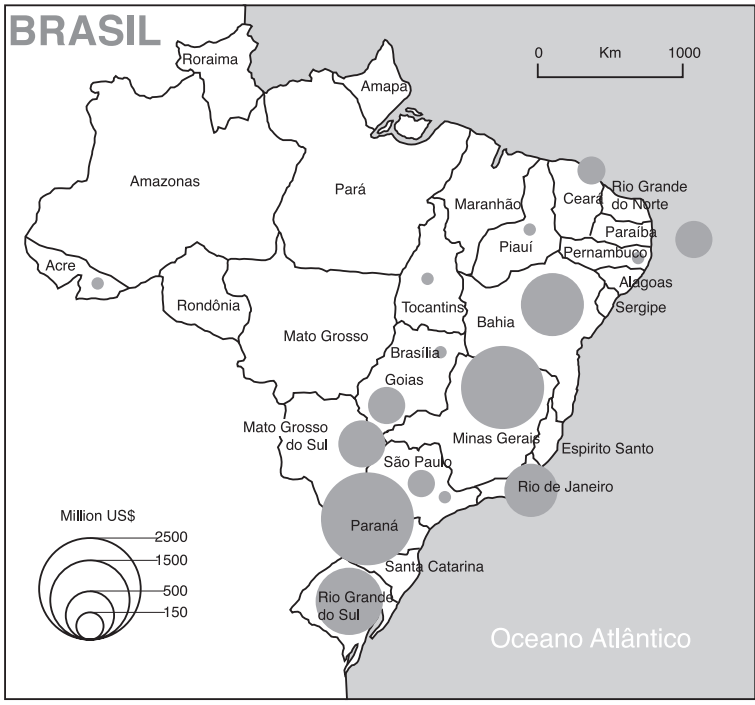

Fonte: Rodríguez-Pose e Arbix, 2001.

Tabela 1

Marcas e Fábricas da $1^{a}$ e $2^{a}$ Migração (1957-1995)

\begin{tabular}{|c|c|c|c|c|}
\hline PRODUTOS & INÍCIO & PRODUÇÃO & REGIÃO & FÁBRICAS \\
\hline Ford & $\begin{array}{c}\text { Automóveis } \\
\text { Comerciais leves } \\
\text { Caminhões }\end{array}$ & 1957 & São Paulo & 4 \\
\hline GM & $\begin{array}{c}\text { Automóveis } \\
\text { Comerciais Leves } \\
\text { Caminhões }\end{array}$ & 1957 & São Paulo & 2 \\
\hline Mercedes & $\begin{array}{l}\text { Caminhões } \\
\text { Ônibus }\end{array}$ & 1957 & São Paulo & 2 \\
\hline Scania & $\begin{array}{c}\text { Caminhões } \\
\text { Ônibus }\end{array}$ & 1957 & São Paulo & 1 \\
\hline Toyota & Comerciais leves & 1959 & São Paulo & 1 \\
\hline $\mathrm{VW}$ & $\begin{array}{c}\text { Automóveis } \\
\text { Comerciais leves }\end{array}$ & 1957 & São Paulo & 2 \\
\hline Fiat & $\begin{array}{c}\text { Automóveis } \\
\text { Comerciais leves }\end{array}$ & 1976 & Minas Gerais & 2 \\
\hline Volvo & $\begin{array}{l}\text { Caminhões } \\
\text { Ônibus }\end{array}$ & 1979 & Paraná & 2 \\
\hline
\end{tabular}

Não inclui tratores e máquinas agrícolas.

Fonte: Anfavea, Panorama Setorial. 
Tabela 2

$3^{\text {a }}$ Migração: Novas Marcas e Novas Fábricas (1996-2002)

\begin{tabular}{|c|c|c|c|c|}
\hline \multicolumn{5}{|c|}{ Novas Fábricas de Montadoras Anteriormente Instaladas } \\
\hline Produtos & Início & Produção & Região & Fábricas \\
\hline Fiat - Iveco & Caminhões & 1999 & Minas Gerais & 1 \\
\hline Ford & Automóveis & 2002 & Bahia & 1 \\
\hline GM & Automóveis & 2000 & Rio Grande & 1 \\
\hline Mercedes & Automóveis & 1999 & Minas Gerais & 1 \\
\hline Toyota & Automóveis & 1998 & São Paulo & 1 \\
\hline VW & Caminhões & 1996 & Rio de Janeiro & 1 \\
\hline VW - Audi & Automóveis & 1999 & Paraná & 1 \\
\hline \multicolumn{5}{|c|}{ Marcas e Fábricas Novas } \\
\hline Chrysler & Comerciais leves & 1998 & Paraná & 1 \\
\hline Honda & Automóveis & 1997 & São Paulo & 1 \\
\hline Mitsubishi & Comerciais leves & 1998 & Goiás & 1 \\
\hline Navistar & Caminhões & 1998 & Rio Grande & 1 \\
\hline Peugeot & Automóveis & 2001 & Rio de Janeiro & 1 \\
\hline Renault & Automóveis & 1999 & Paraná & 1 \\
\hline Land Rover & Comerciais leves & 1999 & São Paulo & 1 \\
\hline
\end{tabular}

* Não inclui quatro fábricas de motores construídas no período (Chrysler/BMW, VW, Renault, Fiat)

** Não inclui fábricas de tratores e máquinas agrícolas.

Fonte: Anfavea, Panorama Setorial.

Essa nova realidade fabril, em que somente as montadoras aplicaram cerca de US\$ 17 bilhões entre 1995 e 2000, aumentou em 25\% a capacidade industrial instalada ${ }^{2}$, além de ter alterado espacial e qualitativamente a disposição da produção de autoveículos, criando novos pólos produtivos a partir da instalação de modernos equipamentos fabris. Em aberto contraste com o ocorrido nos anos de 1950 e 1960, a maior parte das novas fábricas de autoveículos foram construídas fora da região metropolitana de São Paulo, tradicional centro industrial brasileiro (Tabelas 1 e 2).

\section{A competição territorial nos países em desenvolvimento}

No campo das teorias neoclássicas e do crescimento endógeno, as teses mais dominantes procuram demonstrar que o aprofundamento dos processos de integração das economias em desenvolvimento com os circuitos econômicos internacionais deveria gerar mais vantagens do que desvantagens.
Nessa perspectiva, considera-se que qualquer aumento nos fluxos de comércio e de informação entre os países desenvolvidos e os em desenvolvimento tenderia a gerar efeitos competitivos e reestruturadores que, a médio prazo, aumentariam a eficiência dessas economias com a elevação significativa da produtividade do trabalho (Grossman e Helpman, 1991). Isso significa que as economias abertas tenderiam a exibir um crescimento maior e mais rápido do que as economias fechadas, e também seriam mais aptas a se beneficiar dos processos de transferência tecnológica, como indicaram Levine e Renelt (1992). Ou seja, os países em desenvolvimento que conseguissem intensificar suas trocas internacionais com países tecnologicamente mais avançados estariam mais habilitados a aumentar sua produtividade, a partir do domínio sobre novos padrões produtivos e novos processos e produtos, praticamente impossível de ser alcançado com seus próprios recursos (Coe e Helpman, 1995; Coe, Helpman e Hoffmeister, 1997). 
Essa visão dominante nos últimos vinte anos foi trabalhada empiricamente por Sachs e Warner em vários estudos e pesquisas. Em artigos de 1995 e 1997, esses dois autores estabeleceram uma clara relação entre as taxas de crescimento e o grau de abertura das economias nacionais. Analisando dados de vários países a partir da década de 1960, Sachs e Warner apontaram para o grau maior de convergência entre as economias em desenvolvimento mais abertas, em contraste com divergência anotada entre as economias mais fechadas: "economias abertas podem vivenciar um processo de convergência de renda mais rápido do que as economias fechadas, já que a mobilidade internacional do capital e da tecnologia pode acelerar a transição para uma renda mais estável" (Sachs e Warner, 1997, p. 187).

De modo complementar, outros autores procuraram estender o alcance dessas teorias para um nível intermediário, regional. Nessa dimensão, o aprofundamento da integração econômica dos países em desenvolvimento também exerceria, não somente um impacto positivo sobre a eficiência econômica, mas também seria capaz de promover uma diminuição das desigualdades regionais. A desativação dos mecanismos hierarquizados do período desenvolvimentista e sua substituição por processos de alocação de recursos e investimentos mais dependentes do mercado e das decisões de agentes econômicos individuais estaria levando os países atrasados a "aumentar a demanda por trabalhadores não qualificados, mas alfabetizados" (Wood, 1994, p. 8). Como os maiores contingentes desses trabalhadores estão concentrados na periferia dos países em desenvolvimento, as regiões relativamente mais atrasadas desses países tenderiam a se beneficiar muito mais com a abertura de suas economias do que as áreas mais industrializadas. Esse processo resultaria, assim, na diminuição das disparidades regionais dos países em desenvolvimento (Wood, 1994; Williamson, 1997; Duranton, 1999).

Essas teorias, no entanto, são alvo de intensa polêmica. Vários autores contestam os pressupostos, as projeções e a metodologia das visões que procuram apresentar a intensificação do comércio internacional como portadoras em si de tantas virtudes. Para a presente discussão, o que nos interessa é a sua adequação - ou não - para explicar o curso recente da abertura econômica e da regionalização das políticas públicas no Brasil. Nesse sentido, é importante salientar que essas interpretações - que prevaleceram nos círculos governamentais dos anos de 1990 - encontram dificuldade para explicar por que a abertura econômica, contrariamente às suas expectativas, não tem dado origem a dinâmicas regionais significativamente virtuosas.

De um ponto de vista teórico, a análise tornou-se ainda mais sofisticada a partir do aprofundamento da integração da economia mundial. Uma série de estudos mostra que essa integração libera forças centrífugas e demandas por maior autonomia regional, no sentido de que a responsabilidade pelas políticas de desenvolvimento sejam transferidas para os governos subnacionais (Keating, 1998; Rodríguez-Pose, 1998). Após anos de tutela estatal, este seria um fator extremamente positivo para muitas regiões e municípios que começam a perceber que a integração econômica pode mudar radicalmente sua condição ao abrir novas oportunidades para o seu próprio desenvolvimento (Markusen, 1996).

A disputa agressiva pelos investimentos estrangeiros que voltaram a fluir para o Brasil na década de 1990 é consistente com essa abordagem, uma vez que a prosperidade de cada região vem sendo cada vez mais percebida como dependente da capacidade de cada localidade de se dedicar a estratégias competitivas efetivas para atrair novos empreendimentos (Cheshire e Gordon, 1996; Budd, 1998; Cox e Mair, 1988).

De acordo com Cheshire e Gordon, a competição territorial sempre se configura como um "processo implícito ou explícito de disputa com outras regiões" (1996, p. 385), processo este que inclui uma série enorme de incentivos econômicos, de infra-estrutura e mesmo de formação e qualificação de fornecedores e trabalhadores.

No entanto, a competição territorial é orientada pela lógica de cada região, que busca, antes de mais nada, aumentar sua própria eficiência. Nesse sentido, o fato de a disputa não ter como objetivo a diminuição de eventuais disparidades 
entre as regiões, as conseqüências da competição territorial podem vir a neutralizar eventuais efeitos positivos derivados do processo de integração econômica. Como Cheshire e Gordon (1998) enfatizaram, a competição territorial é positiva quando consegue promover o crescimento e o bem-estar econômico local e nacional. Porém, seus resultados podem mostrar-se negativos. Serão classificados como de soma-zero, quando qualquer aumento no bem-estar local é alcançado às custas do bem-estar de outras regiões; ou como puro desperdicio, quando a competição territorial representa não mais do que uma simples dilapidação de recursos. Neste último caso, os efeitos da competição territorial em termos da melhoria do bem-estar a longo prazo tendem a ser insignificantes em termos locais e podem mesmo acarretar conseqüências econômicas perversas em outras regiões.
No caso da indústria automotiva brasileira, a entrada de novos investimentos na segunda metade da década de 1990 foi mediatizada pela emergência de novos atores econômicos, que interceptaram sua trajetória, distorceram sua alocação e empenharam nas negociações com as grandes corporações recursos de monta para suas regiões. $\mathrm{Na}$ maior parte dos casos, os custos envolvidos são excessivamente altos, sendo que a contraparte das empresas, além de indefinida e incerta, é geralmente superdimensionada pelos órgãos governamentais envolvidos.

Por um lado, a entrada em cena de governadores e prefeitos na implementação de políticas regionais pró-ativas foi positiva ao ajudar a desconcentrar a indústria automotiva; por outro, foi negativa ao dissipar valiosos recursos públicos e ao introduzir grande turbulência ao já precário equilíbrio federativo. Se acrescentarmos o despreparo técnico de Estados e municípios para enfren-

Figura 2

Resultados Locais e Globais da Competição Territorial

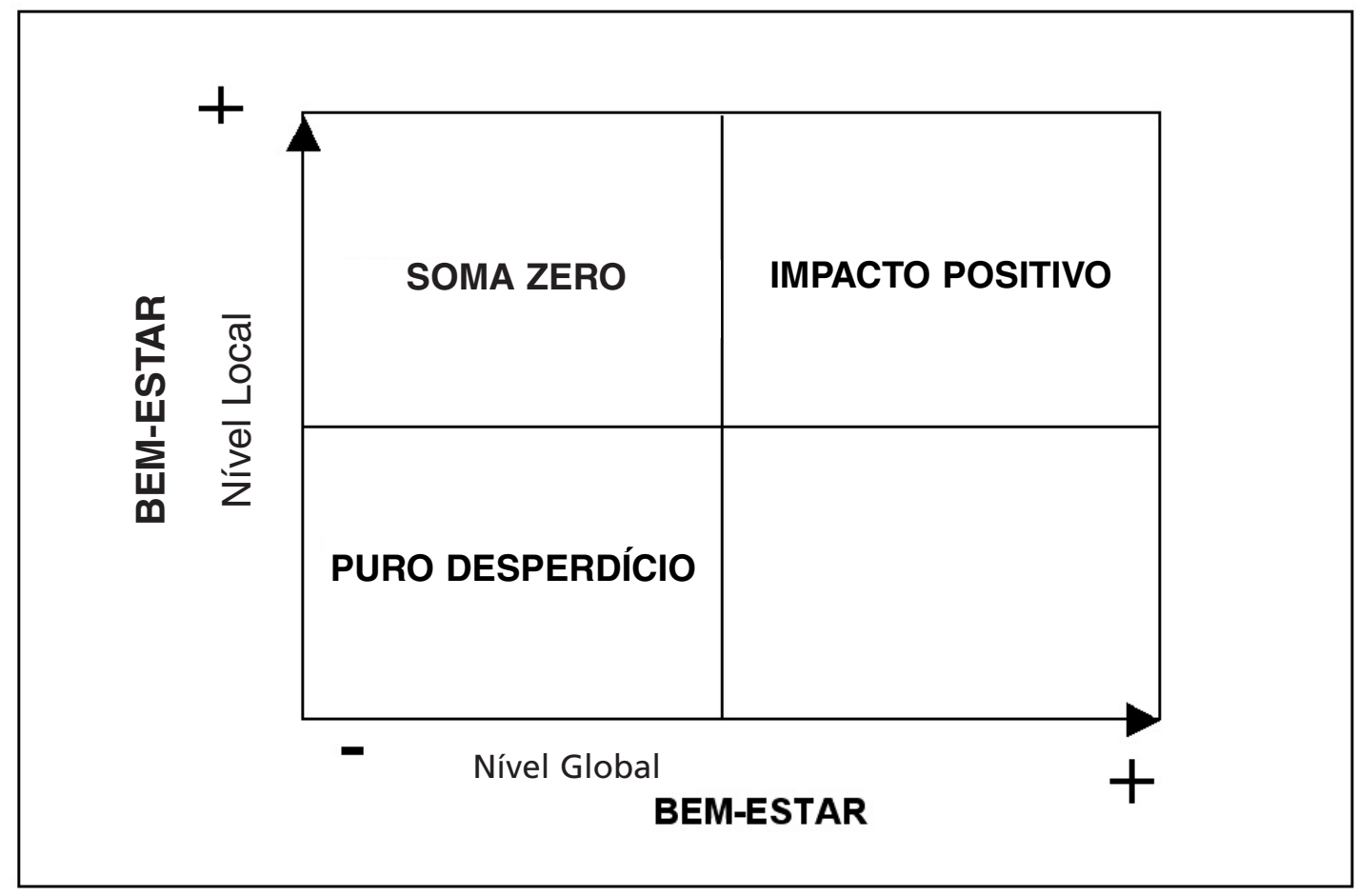

Fonte: Rodríguez-Pose e Arbix, 2001. 
tar as negociações com as grandes empresas e a carência de instituições voltadas para o desenvolvimento que essa disputa tem revelado, não teremos um desenho animador dessa experiência.

\section{A descentralização e suas razões}

Quais seriam as razões que poderiam bem explicar a desconcentração industrial da indústria de autoveículos? Por que as montadoras se afastaram das áreas que ofereciam vantagens econômicas externas - com disponibilidade de trabalho qualificado e de uma rede já existente de fornecedores - e optaram por construir suas novas plantas fora do centro industrial do país?

As razões que explicam a atual dispersão dos Investimentos Diretos Externos (IDE) são múltiplas.

Em primeiro lugar, vem a questão dos custos trabalhistas em combinação com o que Wood (1994) considerou a principal força do comércio Norte-Sul: a capacitação. A abertura da economia estaria levando os países em desenvolvimento a se especializar na produção de bens manufaturados e relativamente indiferenciados, uma vez que oferecem mão-de-obra alfabetizada mas relativamente não-qualificada. O setor automobilístico encaixa-se nessa categoria e os salários mais baixos em países como o Brasil - somados aos incentivos dos mercados em expansão - atuam como uma isca para as montadoras. As diferenças salariais no interior do Brasil e a redução do gap educacional no país nos últimos anos levaram as montadoras a buscar as regiões com menores custos trabalhistas. Nesse sentido, os trabalhadores da Grande São Paulo estão em relativa desvantagem em relação aos do restante do país, pois o custo da hora trabalhada nas plantas automotivas na região do $\mathrm{ABC}$ é praticamente $40 \%$ maior que em outras montadoras. ${ }^{3}$

Em segundo lugar, São Paulo possui uma força de trabalho mais inclinada ao conflito do que no restante do país. As montadoras do $\mathrm{ABC}$ foram o berço do movimento sindical mais atuante no país no final dos anos de 1970 e na década de 1980. Os níveis de filiação e de organização sindical são altos. Desde o final dos anos de 1970, os sindicatos locais tiveram sua história vinculada aos conflitos com as empresas, criando uma imagem que persistiu ao longo do tempo, apesar das significativas mudanças políticas e das práticas implementadas por seus dirigentes sindicais.

O terceiro fator que ajuda a compor o quadro explicativo da recente descentralização é a alteração de algumas das condições que facilitaram a concentração industrial nos anos de 1950 e 1960. Naquele período, a frágil infra-estrutura rodoviária e ferroviária no país e a concentração do mercado e do trabalho qualificado na região Sudeste contribuíram para que o governo federal escolhesse a região do $\mathrm{ABC}$ como o coração da produção automotiva. No entanto, a melhoria da malha rodoviária e da infra-estrutura em outras regiões do país nas últimas três décadas, somadas à necessidade de se aproximar de novos mercados, serviram de grande estímulo para que as montadoras selecionassem novas áreas para seus investimentos.

Em quarto lugar, havia, na época, previsões bastante otimistas em relação ao Mercosul. A exploração simultânea do mercado argentino e dos novos mercados brasileiros, assim como a possibilidade de construção de um sistema produtivo complementar no Cone Sul - com a perspectiva de uma grande racionalização de custos a partir da divisão de trabalho entre as fábricas já existentes nos vários países - conformou-se como um grande atrativo para a alocação de novas plantas, em especial mais ao sul do país.

Se é certo que os fatores acima descritos ajudam a entender as dificuldades que a região metropolitana de São Paulo enfrenta para atrair novos investimentos, não são suficientes para explicar o processo de descentralização em curso. O principal fator capaz de explicar o processo relativo de desconcentraçao da indústria automobilística no Brasil é a guerra fiscal deflagrada entre Estados e municípios brasileiros à procura de investimentos.

\section{O jogo da guerra}

Como dissemos, a ampliação dos fluxos de capital estrangeiro fomentou processos de compe- 
tição territorial que podem diminuir eventuais efeitos benéficos dos investimentos. O distanciamento do governo federal da definição de políticas regionais despertou o apetite dos mais distintos Estados brasileiros: do Rio Grande do Sul ao Amazonas, de Rondônia à Santa Catarina, a esmagadora maioria dos Estados compete hoje para atrair novos investimentos.

Deflagrado pelo governo federal com a edição do Novo Regime Automotivo (1995) - fundamental para que as montadoras tomassem a primeira decisão de investir no Brasil - esse processo passou, num segundo momento, a contar com a intervenção dos governadores e com a utilização crescente de incentivos, subsídios e isenções fiscais, como forma de atrair as grandes empresas para seus territórios.

Fabricantes aqui instalados desde os anos de 1950, assim como novas marcas aproveitaram-se dos benefícios oferecidos, em uma situação que a América Latina voltava a se colocar no campo de interesses das multinacionais do automóvel. Ou seja, conjunturalmente:

1. O Brasil havia derrubado a inflação em 1994, retomando o controle sobre sua moeda e contava com uma economia relativamente estável.

2. O Mercosul, como já registramos, aparentava solidez.

3. Fundamentalmente, o mercado brasileiro de automóveis apresentava uma relação habitante-por-veículo muito mais promissora do que os mercados saturados dos países avançados ou do que a Argentina. ${ }^{4}$ A possibilidade de os fabricantes crescerem a médio e longo prazo no Brasil era muito maior.

4. O crescimento exuberante que o mercado doméstico de veículos apresentou a partir de 1993, ${ }^{5}$ somado às vantagens oferecidas pelo governo federal com o Novo Regime Automotivo para as empresas instaladas no Brasil, proporcionou oportunidades imperdiveis para as montadoras.

Esses condicionantes macroestruturais foram determinantes para impactar os processos decisórios primários nas matrizes das montadoras. As primeiras decisões de reinserir a América do Sul - e o Brasil em particular - no mapa de novos investimentos automotivos foram tomadas antes da deflagração da guerra fiscal.

Apenas num segundo momento, após a seleção e a escolha do país receptor do investimento, é que as montadoras se voltaram para a escolha da região exata que abrigaria as novas fábricas. Procurando a oferta mais adequada aos seus interesses - técnica, econômica e financeiramente -, as montadoras passaram a receber ofertas, em escala crescente, para melhor alocar seus investimentos. Não é por outro motivo que as comunidades, ONGs, associações, sindicatos, movimentos e a população em geral foram mantidos a uma prudente distância dessas articulações.

Embora as negociações entre as montadoras e os Estados tenham assumido formas distintas, os principais acordos apresentaram-se como variações em torno de um mesmo tema. Em contrapartida ao estabelecimento de uma nova planta automotiva em seu território, o Estado e a cidade escolhidos ofereceram uma série de incentivos que incluem, invariavelmente, os seguintes pontos:

1. Doação de terrenos para a instalação da planta ou de grande parte dele.

2. Fornecimento da infra-estrutura necessária para a preparação da área. Isso inclui, em geral, a infra-estrutura viária e logística, mas abrange também, em vários casos, ligações ferroviárias e desenvolvimento de terminais portuários.

3. Isenção de impostos estaduais e locais por períodos não inferiores a dez anos. O mesmo vale para as taxas locais. Em vários casos, o acordo inclui a isenção de impostos na importação de peças e veículos.

4. Concessão de empréstimos pelo Estado (por meio de órgãos ou bancos estatais) a taxas muito inferiores às do mercado.6

5. Uma série de cauções e garantias estatais, financeiras e legais.

6. Uma série de benefícios adicionais, que variam de acordo para acordo, envolvendo desde fornecimento de transporte público aos trabalhadores e creches para seus filhos a diversas medidas ambientais. 
Algumas condições variaram de acordo com o poder de barganha de cada empresa e de cada Estado. Mas os termos dos protocolos favoreceram inevitavelmente as empresas, como podemos constatar pelos exemplos a seguir.

Um dos primeiros Estados a se engajar na guerra fiscal foi o Estado do Paraná. Em março de 1996, o governo do Estado, o município de São José dos Pinhais e o Fundo de Desenvolvimento Econômico assinaram um protocolo com a Renault. ${ }^{7}$ As condições do acordo estabeleciam que a Renault deveria construir uma planta em São José dos Pinhais até o início de 1999, sendo que 60\% do capital total do empreendimento caberia à multinacional francesa que, além disso, geraria 1.500 empregos diretos e pagaria multa de $\mathrm{R} \$ 50,5 \mathrm{mi}-$ lhões se a planta fosse desativada em menos de vinte anos. O Estado do Paraná e o município de São José dos Pinhais doariam 2,5 milhões de $\mathrm{m}^{2}$, providenciariam a infra-estrutura e a logística necessárias, incluindo acessos rodoviários e ferroviários, assim como uma área exclusiva para a empresa no porto de Paranaguá. O suprimento de energia seria feito a uma taxa $25 \%$ inferior à praticada pelo mercado. $40 \%$ do capital investido (com um teto de US\$ 300 milhões) seriam de responsabilidade do Estado do Paraná. Os empréstimos oficiais à Renault seriam vinculados aos níveis de produção da empresa, não teriam correção inflacionária e começariam a ser pagos dez anos depois de iniciadas as operações. A Renault receberia ainda isenção de impostos locais por dez anos, assim como todos os fornecedores que viessem a se instalar em sua área industrial. Em outubro de 2001, o governo do Paraná concordou em conceder mais cinco anos para que a Renault (assim como para a Volwswagen/Audi) começasse a recolher o ICMS devido. Esse novo prazo vem se somar aos quatro anos de carência que as empresas já haviam garantido para si quando assinaram o protocolo de intenções ao se instalarem no Paraná. Com isso, tanto a Renault, como a Volkswagen/Audi, só deverão começar a pagar ICMS em 2009. Como ocorreu com o conjunto das negociações, o novo acordo com as montadoras foi mantido em sigilo pelo governo do Paraná. A ampliação do prazo para o início do pagamento parcial do ICMS foi concedido pelo governo depois que Lei de Responsabilidade Fiscal inviabilizou os financiamentos prometidos à Renault por meio do Fundo de Desenvolvimento Econômico (FDE). O novo acordo teve como base um novo programa de incentivos, denominado Prodepar, criado em julho de 2001, em substituição ao programa Paraná Mais Empregos, contestado na Justiça pelo Estado de São Paulo e derrubado pelo Supremo Tribunal Federal. O Prodepar, além de prever um adiamento de sessenta meses no recolhimento de ICMS para empresas que vierem a se instalar ou a realizar novos investimentos agregando tecnologia, procura contornar eventuais obstáculos criados pela Lei de Responsabilidade Fiscal.

As condições para o acordo da General Motors (GM) com o governo do Rio Grande do Sul também foram extremamente generosas para com a montadora. O protocolo assinado previa US\$ 310 milhões de empréstimos oficiais - destinados a financiar a compra do terreno -, a uma taxa de juros de $6 \%$ ao ano, a serem pagos a partir do ano 2002. A isenção de impostos seria de quinze anos, sendo que o Estado ainda teria de fornecer infraestrutura e os serviços de água, eletricidade, gás natural e sistema de telecomunicações a taxas subsidiadas. ${ }^{8}$ Mais ainda, o Estado deveria construir um porto privado e um canal marítimo de acesso, assim como garantir transporte público à fábrica.

A Ford também assinaria um protocolo com o Estado do Rio Grande do Sul alguns meses mais tarde, espelhado no acordo da GM. Em troca, a montadora americana construiria uma planta para produzir 100 mil carros, com investimentos entre US\$ 500 milhões a US\$ 1 bilhão. Para tanto, o Estado do Rio Grande do Sul se comprometeria a doar terreno, infra-estrutura, terminal portuário, e as isenções também fariam parte do acordo. ${ }^{9}$

Num certo sentido, os benefícios oferecidos não se distinguem em qualidade dos tradicionalmente utilizados no mundo todo para a atração de novas empresas. No entanto, ao realçarmos o volume de recursos públicos envolvidos - suficientes para cobrir o custo inicial dessas novas fábricas - e a incerteza de retorno para o setor público dessas inversões, seja no médio ou longo 
prazo, teremos um quadro nada otimista sobre os impactos dessa onda de IDEs no desenvolvimento das regiões menos industrializadas e para o país como um todo.

\section{A escalada da guerra}

Do ponto de vista nacional, a celebração dos acordos com os incentivos estaduais e municipais indica perdas para o conjunto do país, uma vez que a decisão do investimento fora tomada previamente à deflagração da disputa interterritorial. Para as montadoras, essa competição foi utilizada para reduzir o volume de seus investimentos, compensados pela nova intervenção de recursos públicos.

Em segundo lugar, os ganhos decorrentes da descentralização industrial, em especial na teoricamente anunciada capacidade corretora de desigualdades, precisam ser relativizados. Com exceção da revoada da Ford para a Bahia, todos os novos investimentos concentraram-se no que Campolina Diniz caracterizou como o polígono mais industrializado e rico do país.

Em terceiro, as análises que apontavam para uma rápida convergência do volume de incentivos oferecidos para um mesmo nível - já que todos os contendores tenderiam a equalizar seus lances -, minimizando a importância da disputa, tiveram suas previsões contrariadas pelos fatos. Num curto espaço de tempo, os incentivos evoluíram significativamente. Localizamos nessa evolução quatro fases distintas, marcadas sucessivamente por um volume crescente de recursos públicos envolvidos, em nível municipal e estadual e federal.

O primeiro momento, aberto pela edição do Novo Regime Automotivo, estendeu-se até o início da ofensiva deflagrada pelo governador Jaime Lerner (PFL) em 1996. Até os lances do Paraná, o nível da disputa no Brasil mal se diferenciava da prática disseminada pelo país de oferecer incentivos locais para favorecer o deslocamento industrial. Nesse primeiro estágio, encontra-se as instalações em Resende (RJ) e São Carlos, pela Volkswagen (para a instalação de suas fábricas de caminhões e motores) e, no final, em Juiz de Fora, com a então Mercedes-Benz (para produzir o Classe A).
Num segundo momento, as ofertas do Estado do Paraná quebraram significativamente os níveis do patamar anterior e passaram a dominar a cena da guerra fiscal, conseguindo atrair a Renault, VW-Audi e Chrysler, além de uma fábrica de motores da Chrysler/BMW. Nessa fase, não só o volume das ofertas cresceu, como também a qualidade do que passou a ser oferecido. No acordo com a Renault, por exemplo, o Estado do Paraná assumiu a responsabilidade de parte dos investimentos diretos, voltando, desde a venda da velha Fábrica Nacional de Motores (FNM), até a cuidar diretamente da produção de autoveículos. As principais montadoras que haviam anunciado sua intenção de construir novas fábricas no Brasil aceitaram as condições do Paraná, que conseguiu criar em seu território o segundo pólo automotivo brasileiro. A disputa mostrar-se-ia mais profissional a partir desse estágio. Grupos especializados entraram em cena, contatando as montadoras, viajando ao exterior para apresentações junto às matrizes, tentando convencê-las das vantagens econômicas oferecidas por alguns Estados. Os Estados do Rio Grande do Sul, Paraná, Santa Catarina, Rio de Janeiro, Bahia e mesmo alguns municípios do interior de São Paulo contaram com esse tipo de força-tarefa. As vantagens oferecidas pelo Paraná, que dispunha de recursos advindos dos processos recentes de privatização, e a sua engenhosidade institucional e financeira imperaram e decidiram as regras do jogo em todo o país neste segundo momento.

Essa primazia seria quebrada, porém, pelo governador Antônio Britto (PMDB), do Rio Grande do Sul, que teria sucesso na atração da GM e definiria o terceiro formato que a corrida dos incentivos assumiria. A GM, que não via o Rio Grande do Sul como uma de suas prioridades, ${ }^{10}$ passou a demonstrar seu interesse após a oferta do governo que tornava disponível US\$ 310 milhões para a empresa a título de capital de giro e infra-estrutura. O desinteresse da GM transformar-se-ia rapidamente em aberto entusiasmo. Os US\$ $310 \mathrm{mi}-$ lhões iniciais seriam convertidos em US\$ 252 milhões cash, pagos na assinatura do acordo, mais de dois anos antes de a fábrica iniciar sua produção. Foi dessa forma, na expressão de uma das 
autoridades do governo que negociaram com a montadora, que o "RS comprou o passe da GM". A tradicional instabilidade política do país, assim como as constantes alterações de comportamento dos governantes, levaram não só a GM, como também a Ford, a considerar a generosidade gaúcha irrecusável, principalmente porque parte significativa dos incentivos poderia agora ser recebida antecipadamente. Esse mesmo processo tenderia a se repetir com a Ford. No entanto, apesar da semelhança do acordo, o governo do Rio Grande do Sul não tinha mais fôlego financeiro para sustentar a mesma oferta da GM. A saída, aceita pela Ford, foi parcelar o pagamento cash em seis vezes. "Erro imperdoável" da Ford, diriam alguns de seus diretores, pois a história eleitoral colocaria à frente do governo do Estado o ex-prefeito de Porto Alegre, Olívio Dutra (do Partido dos Trabalhadores, PT), que havia feito da crítica desses acordos um ponto expressivo de sua campanha. As relações entre a Ford e o novo governo tornaram-se praticamente insustentáveis com a interrupção do pagamento das cotas acordadas anteriormente $\mathrm{e}$ as pressões do novo governo em renegociar os benefícios diante da difícil situação financeira do
Estado. O resultado foi uma veloz deterioração das negociações, que culminou com a ruptura do acordo e a transferência da montadora para o Estado da Bahia, em junho de 1999.

A quarta fase seria aberta exatamente pelo desdobramento dos conflitos iniciados no Rio Grande do Sul. Desta vez, a canibalização de um Estado da federação por outro realçaria as características perversas da guerra fiscal. Antes mesmo da definição da Ford junto ao governo do Rio Grande do Sul, o governador da Bahia (PFL) iniciaria uma intensa ofensiva para atrair a montadora americana, que chegou até mesmo a incluir anúncios nos grandes jornais afirmando que a Bahia saberia honrar seus compromissos. Um novo conjunto de ofertas seria articulado, envolvendo, desta vez, não só recursos públicos estaduais e municipais, mas também federais. Para que isso ocorresse, a Ford teria que assinar o Novo Regime Automotivo Especial para o Nordeste, Norte e Centro-Oeste que, no entanto, tinha esgotado seu prazo de credenciamento. Esse regime era essencial para superar a oferta gaúcha, já que permitia a concessão de incentivos federais para as empresas para fins de desenvolvimento regional. Neste

\section{Tabela 3}

\section{Exemplos de Custo de Atração de Investimentos}

\begin{tabular}{|c|c|c|c|c|c|c|}
\hline LOCAL & ANO & EMPRESA & $\begin{array}{c}\text { INVESTIMENTO } \\
\text { PÚBLICO } \\
\text { (US\$ mi) }\end{array}$ & $\begin{array}{c}\text { INVESTIMENTO } \\
\text { MONTADORA } \\
\text { (US\$ mi) }\end{array}$ & $\begin{array}{c}\text { EMPREGOS } \\
\text { DIRETOS } \\
\text { MONTADORA }\end{array}$ & $\begin{array}{c}\text { INCENTIVOS } \\
\text { /EMPREGO } \\
\text { (US\$) }\end{array}$ \\
\hline \multicolumn{7}{|c|}{ Brasil } \\
\hline Gravataí (RS) & 1999 & GM & $226.585^{*}$ & 600 & 1.300 & 174.296 \\
\hline Guaíba (RS) & 1999 & Ford & $271.240^{*}$ & 1.000 & 1.500 & 180.296 \\
\hline Juiz de Fora (MG) & 1999 & Mercedes & $228.000^{*}$ & 845 & 1.500 & 152.000 \\
\hline \multicolumn{7}{|c|}{ Estados Unidos } \\
\hline Marysville (Ohio) & 1980 & Honda & 20 & 800 & 5.000 & 4.000 \\
\hline Smyrna (Tennessee) & 1983 & Nissan & 33 & 796 & 1.300 & 25.384 \\
\hline Flat Rock (Michigan) & 1984 & Mazda/Ford & 48,5 & 747 & 3.500 & 13.857 \\
\hline Spring Hill (Tenn.) & 1985 & Saturn/GM & 80 & 4.145 & 3.000 & 26.667 \\
\hline Georgetown (Kent.) & 1985 & Toyota & 149,7 & 823,9 & 3.000 & 49.900 \\
\hline Bloomington (Illinois) & 1985 & Mitsubishi & 83,3 & 600 & 2.900 & 28.724 \\
\hline Lafayette (Indiana) & 1986 & Isuzu & 86 & 490 & 1.700 & 50.588 \\
\hline Tuscaloosa (Alabama) & 1993 & Mercedes & 250 & 400 & 1.500 & 166.667 \\
\hline Spartenburg (C. Sul) & 1994 & BMW & 130 & 450 & 1.200 & 108.333 \\
\hline
\end{tabular}

*Não incluem isenção fiscal estadual e municipal. Repasses iniciais para infra-estrutura + capital de giro. Não incluem repasse para eventuais empresas fornecedoras que se benefiaram dos acordos.

Fontes: Donahue, 1997; Perrucci, 1994; UNCTAD, 1996; SEDAI/RS, 1999 - US\$ 1= R\$ 1,7. 
caso, o Congresso Nacional seria mobilizado pelo então presidente do Senado, Antonio Carlos Magalhães (PFL), que, em acordo com o governo federal, conseguiu dar sobrevida a um já vencido regime especial de modo a incluir no rol de ofertas a isenção de impostos federais. ${ }^{11}$ Os incentivos estaduais e municipais ainda permanecem sigilosos para a opinião pública e os pesquisadores, ainda que todos os indícios sugiram que não se afastaram muito dos oferecidos pelo Rio Grande do Sul. De todo modo, nessa quarta fase, com a entrada no jogo de fundos federais, a guerra fiscal atingiria seu ponto mais elevado. ${ }^{12}$

A relação entre investimentos públicos e empregos diretamente gerados pela montadora constitui uma das formas de se avaliar a qualidade dos programas e iniciativas. Por essa ótica, a tabela 3 mostra que os custos por emprego que os Estados do Rio Grande do Sul e Minas Gerais estão pagando para atrair os investimento da GM e da Mercedes são mais elevados do que todas as experiências nos Estados Unidos, inclusive as mais polêmicas, que mais custaram aos cofres públicos estaduais, como no Alabama e na Carolina do Sul. Se incluirmos a renúncia fiscal e as perdas financeiras dos Estados poderemos afirmar que a guerra fiscal no Brasil está entre as mais caras do mundo.

Os dados da renúncia fiscal são de difícil acesso. Além de serem variáveis dependentes do desempenho das novas fábricas e da receptividade de seus produtos, os governos guardam a sete-chaves essas informações, tidas como segredo industrial. ${ }^{13}$

\section{A sedução dos governos}

A capacidade de fixar e alterar o destino de seus equipamentos dá às empresas grandes e novas vantagens em sua negociação com os Estados nacionais e com seus trabalhadores. Com as inovações tecnológicas e os novos conceitos produtivos, as corporações potencializaram a mobilidade de seus investimentos, permitindo a coordenação e a instalação da produção numa escala geográfica gigantesca. Ou seja, é a capacidade de se mover, mais do que o próprio movimento, que acaba condicionando as escolhas governamentais (Thomas, 1997).
Essa nova mobilidade das montadoras está na raiz dos crescentes privilégios que têm recebido nos últimos anos pelo mundo afora. Isso porque amplia seu rol de opções e reduz os custos de investimento e de desinvestimento; diminui o impacto de eventuais sanções dos Estados; permite que as empresas se instalem em áreas com menor ou nenhuma tradição sindical, a procura de baixos salários, alterando os mecanismos de distribuição de renda em seu benefício; e facilita as transações intrafirmas.

Houve época em que a preocupação com a melhor forma de se contrabalançar a exagerada dependência externa de capitais marcava a pesquisa acadêmica. Nos dias de hoje, porém, a ênfase tem se mostrado outra, inclusive na América Latina, onde as estratégias para a economia e a sociedade estiveram sintonizadas com a maré reestruturante que se articulou em torno do combate à inflação, controle da moeda, ajuste fiscal, cortes orçamentários, privatização e desregulação. No plano internacional, o caminho adotado pela maior parte dos países latino-americanos realçou a necessidade de integração com os mercados globais, servindo-se, para tanto, da diminuição das restrições aos fluxos comerciais, da atração de investimentos externos (diretos e em portfólio) e de tecnologia. Os trabalhos que tentam desdobrar essa política buscam caracterizar as multinacionais como agentes imprescindíveis do desenvolvimento (Julius, 1990; Brittan, 1995) e a sugerir que os distintos países se amoldem a essas empresas (Stopford, 1994).

Nesse dispositivo, as corporações sempre aparecem como atores de primeira grandeza, seja pelo seu papel crescente no processo de globalização, seja porque estariam se tornando cada vez mais stateless corporations, o que as credenciaria a realocar as atividades de $\mathrm{P} \& \mathrm{D}$, por exemplo, em países periféricos. Invariavelmente, as análises com esse perfil destacam a convergência de interesses existente entre as multinacionais e os países hospedeiros. Eventuais atritos com as orientações dessas empresas tenderiam a afastá-las para outras regiões, e só um comportamento carregado de ideologia deixaria de reconhecer que os IDEs são "uma fonte extra de capital e de knowhow gerencial, uma contribuição ao saneamento da balança comercial, 
um estímulo ao aumento de produtividade, dos empregos, da competição, da produção racional e de transferência de tecnologia" (Brittan, 1995, p. 2).

Existe também uma série de outros estudos (Narula en Dunning, 2000; Mortimore, 2000; Rodriguez e Rodrik, 2000; Amsden, 2001; Lall, 1993 e 1994) que polemizam com essas concepções. Esses autores, apesar de diferenças entre suas pesquisas, mostram como a globalização não afetou todas as regiões e os países na mesma extensão e intensidade. Narula e Dunning enfatizaram que "o caminho do desenvolvimento para um país atrasado depende muito de recursos específicos, instituições, estrutura econômica e do tecido políticoideológico e cultural de seu tecido social" (2000, p. 4). Mostraram também como as empresas dos países em desenvolvimento têm enormes dificul- dades para compartilhar tecnologia às multinacionais, uma vez que os principais centros produtores de inovação estão intensamente enraizados em poucos e específicos territórios. São, portanto, protegidos pelas corporações.

Mortimore, baseado nos modelos de Dunning, demonstrou como a América Latina atraiu, nos anos de 1990, um investimento estrangeiro basicamente "reativo, de segundo ou de terceiro nível, de corporações que procuram aperfeiçoar a eficiência de seus sistemas produtivos regionais; e não o investimento direto de primeiro nível destinado a conquistar os mercados internacionais" (2000, p. 1623). Em outras palavras, a América Latina (com exceção do México, que se voltou para abastecer o mercado americano) está recebendo praticamente um investimento defensivo, de corporações que buscam

Tabela 4

Orientação do Investimento Externo na América Latina - 1990s

\begin{tabular}{llll}
\hline SETOR & PrimárIo & INDÚstria & SERVIÇOS \\
\hline Foco nos Recursos & Petróleo, Gás: & \\
Naturais & Venezuela, Colômbia, & \\
& Argentina; & \\
& Minerais: Chile, & \\
& Argentina, Peru & Automotivo: Mercosul; \\
& & Químico: Brasil; \\
Foco no Acesso a & Agro-indústria: \\
Mercados: industria & Brasil, México, \\
& & Argentina \\
\hline
\end{tabular}

Foco no Acesso

a Mercados: serviços

Sistema Financeiro: Brasil, México, Chile, Argentina; Telecomunicações: Brasil, Argentina, Chile; Peru Energia elétrica: Brasil, Colômbia, Argentina, América Central; Distribuição Gás: Argentina, Brasil, Chile, Colômbia

Foco na eficiência

Foco em ativos estratégicos (especialmente tecnologia)
Automotivo: México; Eletrônico: México, Caribe; Têxtil, Vestuário: Caribe, México

Fonte: Mortimore, 2000. Para a tipologia, ver Dunning, 1998. 
manter uma participação previamente existente ou que buscam acessar novos mercados. O impacto sobre as economias nacionais desse investimento estrangeiro defensivo (como no caso da indústria automotiva brasileira) é muito menos positivo do que os investimentos das corporações que "buscam eficiência" (como na indústria mexicana de autoveículos), ou dos investimentos em "ativos estratégicos" (os de primeiro nível), que promovem mais intensamente as exportações, a qualificação dos trabalhadores e a qualidade dos produtos (Mortimore, 2000, p. 1619).

Rodrik e Rodriguez (2000) refizeram a trajetória dos principais autores que tentaram mostrar os impactos positivos da liberalização comercial para os países em desenvolvimento (Sachs e Warner, 1995; Frenkel e Romer, 1999; Edwards, 1998) e encontraram pouca evidência de que a abertura comercial e os investimentos estrangeiros, em si, estejam associados ao crescimento econômico.

Pesquisando os países em desenvolvimento, Lall procurou mostrar a redução efetiva no universo das suas escolhas estratégicas quando os governos passam a aceitar passivamente as políticas das multinacionais. Isso significa que, para esse autor, a passividade teria conseqüências no plano das opções nacionais de longo prazo que, "naturalmente", tenderiam a escorregar para as mãos das corporações. Ou seja, Lall tenta discutir um eventual aumento da incerteza desses países sobre seu futuro. Explicitamente, seus comentários não pretendem reacender velhas polêmicas, que procuravam explicar os entraves no desenvolvimento a partir das ligações com as multinacionais, mas, com os olhos nas experiências asiáticas, o que se sugere é a rejeição do laissez-faire como opção política de governo em relação às grandes corporações.

As discussões de Amsden (2001) e Jung-en Woo (1991) sobre a Coréia, assim como as de Wade (1990) sobre Taiwan, podem ser especialmente ilustrativas dessa discussão. Ainda que esses países tenham buscado atrair IDEs, trabalharam intensamente para que a tecnologia e o capital ficassem sob controle de suas próprias empresas domésticas. Ainda que o número de grandes empresas em Taiwan fosse menor do que na Coréia, os dois governos, ao longo dos anos de 1960, 1970 e 1980, procuraram envolver o grande capital apenas nos projetos que traziam inequivocamente benefícios aos respectivos países.

Esse trabalho seletivo foi completado por mecanismos de restrição à entrada de capital externo e dos direitos de propriedade para estrangeiros nos dois países. Quando os investimentos entravam, a joint venture com o capital nacional colocava-se de imediato como instrumento dedicado ao controle local do investimento e como canal de transferência de tecnologia. Foi dessa forma que o governo coreano procurou restringir ao máximo o número de empresas sob controle integral de capital estrangeiro. As exceções - sempre para os casos de importância estratégica - nunca superaram a casa dos 13\% do total das indústrias manufatureiras. Como resultado dessa política, em meados dos anos de 1980, apenas 5\% das multinacionais instaladas na Coréia eram integralmente controladas pelo capital estrangeiro, um número muito baixo se comparado aos cerca de 50\% no México e $60 \%$ no Brasil. Em Taiwan, em função do pequeno grupo de grandes empresas capacitadas para realizar joint ventures, o número de empresas totalmente controladas pelo capital externo era de 33,5\% em 1985 (Chang, 1998).

Além dos constrangimentos à propriedade e à entrada de capitais, outras barreiras foram utilizados com sucesso pelos dois governos, como a negociação sobre o tipo de tecnologia a ser instalada; seleção de investidores por sua disposição explícita de qualificar a força de trabalho e capacitar as empresas locais; definição de conteúdo local; e metas de exportação.

No entanto, nos anos de 1990, a experiência asiática não fazia parte dos horizontes fixados pelos países latino-americanos que, num movimento pendular, modificaram bastante sua visão sobre os investimentos estrangeiros. Em geral, diferentemente dos anos de 1950, 1960 e 1970, muitos países passaram a procurar e a dar garantias cada vez maiores a esses investimentos e às corporações. Os primeiros resultados dessas mudanças nos países em desenvolvimento, fruto de um balanço ainda por fazer da experiência anterior, produziram grande entusiasmo em relação aos benefícios de- 
correntes de uma rápida liberalização de seus mercados. Após caracterizar a transformação das relações entre governos e multinacionais de uma posição adversa para uma posição cooperativa, Dunning não deixa de insistir para que os governos se concentrem e elaborem políticas para orientar essa relação, mais do "que simplesmente esperar pelos dividendos advindos das atividades dessas empresas" (1998, pp. 281-282). Raymond Vernon já havia alertado para eventuais conflitos que poderiam surgir entre os interesses de governos e das multinacionais em função dos percalços provocados pelo mercado mundial (1998).

Essas indicações, evidentemente, apenas servem para ilustrar que não há um curso natural que faça coincidir os interesses das multinacionais e os interesses de um país, região ou sociedade. Pelo contrário, essa difícil convergência só ocorrerá a partir de definições estratégicas aptas a incorporar essas relações e não a aceitá-las passivamente.

Nesse sentido, as experiências asiáticas com os investimentos estrangeiros e as multinacionais sinalizam que a interdependência econômica é uma via de duas mãos. Quando essa relação se dá entre as multinacionais e os governos estaduais, estrategicamente mais fracos e vulneráveis às políticas e aos políticos de ocasião, muitas vezes uma suposta harmonia imediata de interesses é cantada em verso e prosa para um público carente de boas notícias. A esse respeito, é sempre bom lembrar que o teste definitivo dessa parceria quase nunca acontece na inauguração de uma nova fábrica, mas, infelizmente, quando os tempos se tornam mais difíceis, como no caso da Chrysler, que recentemente fechou suas portas no entorno de Curitiba.

\section{As novas fábricas}

Fazendo tabula rasa de problemas como os apontados anteriormente, os governadores enveredaram rapidamente pelos caminhos da disputa indiscriminada para arrastar as multinacionais, identificadas à modernização, geração de empregos e alta tecnologia.

De modo recorrente, os governos estaduais fizeram previsões exageradas sobre a capacidade de geração de empregos das novas fábricas automotivas. No Paraná, o principal programa existente na época para atrair investimentos era o Paraná Mais Empregos (Governo do Paraná, 1995). Sua estimativa era de que a indústria de autos seria capaz de dinamizar toda a economia do Estado, atraindo fornecedores, novas técnicas e tecnologia e criação de empregos diretos e indiretos. Alguns estudos previram que as novas fábricas da região seriam capazes de criar 100 mil novos empregos indiretos, baseados na estimativa de seis mil empregos diretos prometidos pelas montadoras (um coeficiente multiplicador de dezesseis).

No Rio Grande do Sul, a questão do emprego esteve no centro da disputa territorial. Num primeiro estudo realizado pela Federação das Indústrias do Estado do Rio Grande do Sul (FIERGS), estimou-se que a fábrica da GM em Gravataí (prevista para gerar 1.300 empregos diretos) seria capaz de gerar, ao longo da cadeia, mais de 200 mil novos empregos (150 empregos indiretos para cada emprego direto). Nas palavras do relatório: "Nossa estimativa (conservadora) é que o impacto sobre o emprego ao longo da cadeia produtiva no Estado será de 201 mil empregos" (FIERGS, 1996, p. 4). Quando o debate foi iniciado, a FIERGS divulgou novo relatório diminuindo suas expectativas para 100 mil novos postos de trabalho. Finalmente, em novo estudo, uma terceira previsão seria feita, desta vez em torno de 40 mil empregos a partir da fábrica da GM (cerca de trinta empregos indiretos para cada um direto). $\mathrm{Na}$ Bahia, os números também variaram. Alguns pesquisadores de agências governamentais chegaram a anunciar que os 2.500 empregos diretos que a Ford havia previsto gerariam cerca de 70 mil novos empregos indiretos (um coeficiente de 45).

A falta de consistência dessas projeções apenas expressa a ausência de critérios para a discussão. Alguns estudos apenas reproduzem a vontade dos governadores. Outros procuram apoio nos modelos input-output, sem se dar conta de que as novas fábricas são modularizadas, bem distintas das anteriores, e seu real impacto é difícil de ser previsto, pois as inovações introduzidas são captadas apenas marginalmente por esses modelos.

Na verdade, não há motivo para otimismo no que se refere à criação de empregos. Pelo contra- 
rio. As novas fábricas tendem a aumentar os indicadores de produtividade que são sempre acompanhados de um encolhimento nos postos de trabalho e mesmo de uma redução no número de empregos diretos criados. Essas novas unidades, modularizadas, com nova tecnologia - tanto as de equipamento quanto as que envolvem técnicas organizacionais - foram concebidas, em primeira instância, para serem poupadoras de emprego. Em uma segunda instância, essas novas fábricas tenderão a promover o fechamento de emprego nas unidades mais antigas, como as demissões na Ford e as da VW (Anchieta) mostram claramente. A racionalização industrial ocorre em todo o complexo e na nova divisão de trabalho entre as unidades de uma mesma montadora.

Num certo sentido, os governos subnacionais apenas se adaptaram à tendência dominante em Brasília, que localiza nos investimentos externos uma espécie de passaporte de ingresso no mundo produtivo de alta competitividade e de crescente capacidade exportadora. Gustavo Franco, ex-presidente do Banco Central e figura de proa na condução do Plano Real, afirmava que a nova inserção da economia brasileira em um ambiente marcado pela globalização dependia da expansão dos investimentos externos, apresentados como a razão de ser da política de estabilização monetária, cujo objetivo central era impulsionar "o processo de reestruturação das operações das filiais estrangeiras aqui localizadas na direção de padrões internacionais" (Franco, 1996, p. 12).

O dilema é que não há evidências empíricas de que a participação na disputa interterritorial trará os benefícios apresentados nos documentos e nas justificativas dos governos envolvidos nesse processo. Pelo contrário, tendo em vista as novas características de produção e de tecnologia é pouco provável que essas empresas irão gerar o dinamismo econômico esperado. Certamente trarão benefícios às novas regiões, mas em condições incertas sobre a dimensão e o timing de seu retorno, além do impacto negativo no emprego em áreas de industrialização mais antiga. Ou seja, o mecanismo básico reproduzido pela guerra fiscal possibilita que os benefícios eventuais de algumas regiões sejam constituídos à custa de outras.
Foi diante dessas condições que o pêndulo governamental passou a oscilar entre a ausência de um projeto globalizador e a transferência de responsabilidades para os governos estaduais, que passaram a incluir em suas agendas a questão do desenvolvimento.

A virtude, neste caso, reside na multiplicação de iniciativas estaduais, supostamente ordenadas pelos governadores e que, se fossem criteriosas, poderiam efetivamente interferir na configuração de uma mancha industrial mais equilibrada e menos concentrada nacionalmente. $O$ vício, coetâneo, manifesta-se no desperdício, na politização das decisões, na subserviência às grandes empresas, no despreparo técnico e na ausência de prestação de contas - como nos velhos tempos do desenvolvimentismo autoritário. Não é à toa que os mecanismos mais importantes ligados aos novos processos de industrialização, aqueles que poderiam gerar externalidades positivas, continuam imprecisos, ou mesmo ausentes das preocupações governamentais. Exatamente por isso, os principais contratos assinados entre Estados e montadoras não contêm referências precisas ao impacto sobre a arrecadação de impostos, à geração de emprego, aos processos de aprendizagem, a políticas salariais, qualificação, à recapacitação de empresas, adensamento da malha industrial e à transferência de tecnologia.

Ao entrar na disputa sem definir a contraparte das empresas e tampouco os custos e o retorno para o setor público; ao participar das negociações com as empresas sem estabelecer relações de reciprocidade; sem indicar os meios de controle sobre os planos apresentados; sem se preocupar com a prestação de contas à população; e sem se perguntar pelos direitos do Estado e das cidades, os governadores, de titeriteiros, transformam-se em marionetes. Na verdade, a complacência diante das regras de um jogo feito por poderosas empresas apenas para colonizar o setor público deixa os governadores com "nada, a não ser um fictício poder de decisão" (Habermas, 1971, p. 64).

Essa transferência de poder para as multinacionais pode ser registrada a partir da trajetória de execução dos projetos aprovados. A contração do mercado interno e as dificuldades de exportação 
atualizaram a discussão sobre o excesso de capacidade instalada, aumentando a apreensão entre os governos por eventuais mudanças nas estratégias das corporações. O fechamento recente da nova fábrica da Chrysler no Paraná (que produzia a pick-up Dakota) foi a primeira grande revelação de que os planos das montadoras nem sempre coincidem com os programas governamentais. Sem menosprezar as razões internas que levaram o grupo DaimleChrysler a tomar sua decisão, o menor questionamento sobre a capacidade de absorção dos veículos produzidos, seja do mercado interno seja por meio de exportação, apenas aumenta o grau de incerteza que envolve a atual prática competitiva executada pelos governos estaduais. Embora não existam ainda informações oficiais sobre as perdas do Estado do Paraná nessa empreitada, é certo que o fechamento da fábrica da Chrysler diminui a diversificação e a complementaridade produtiva no interior do pólo paranaense, importante para o desenvolvimento da malha de fornecedores. A Dana, por exemplo, principal fornecedora da Chrysler, e que havia desenvolvido um sistema específico para a montagem das pick-ups, discute agora a sua permanência na região.

Problema semelhante está enfrentando o Estado de Minas Gerais com a produção do Classe A, que não vem apresentando bom desempenho no mercado brasileiro. A interrupção de sua fabricação representaria um duro revés para o governo de Minas Gerais, que planejou e viabilizou seu programa de incentivos, com base nas projeções de venda de um produto de luxo como o Classe A.

Esses dois exemplos recentes apenas realçam alguns componentes da guerra fiscal que já haviam sido anunciados pela interrupção dos planos de investimento da Hyundai e da Kia no Estado da Bahia. Neste caso, ainda que as fábricas não tenham sido construídas, há um débito substancial de uma dessas empresas para com o governo Federal, uma vez que se utilizou de vantagens para a importação de veículos e peças do Novo Regime Automotivo sem que tivesse cumprido sua contraparte, ou seja, a construção da fábrica.

O problema de fundo, porém, acaba escapando ao controle do poder de Estado, uma vez que os interesses e os objetivos das grandes corporações nem sempre coincidem com o interesse público.

Se esses fatores forem considerados, a guerra fiscal não surge como uma disputa de somazero, mas como puro desperdício. Os Estados que disputam para atrair as montadoras estão, de fato, financiando grande parte das instalações e do próprio funcionamento das novas plantas. E isso após os fabricantes terem escolhido o Brasil como o local adequado para seus investimentos. Várias montadoras que haviam anunciado investimentos no Brasil, em regiões próximas a São Paulo, mudaram a localização de suas plantas após a edição do Regime Automotivo Especial para o Nordeste, Norte e Centro-Oeste.

\section{Primeiras conclusões}

Não há sinal disponível que nos permita afirmar que a disputa entre Estados e municípios por novos investimentos está elevando - ou tenderá a elevar - os níveis de bem-estar do país como um todo. Os Estados competiram arduamente por investimentos já destinados ao Brasil. Nesse sentido mais geral, contribuíram para aumentar a cota de transferência de recursos públicos para o setor privado. As condições oferecidas às grandes corporações provocaram um impacto negativo em todo o setor manufatureiro anteriormente instalado, em especial no setor de autopeças, cujas principais empresas nacionais foram absorvidas pelas estrangeiras. Aquele que já foi o maior setor de autopeças em toda a América Latina foi desmobilizado com a entrada de investimentos no setor automotivo.

Qual tem sido a atuação do governo federal em todo esse processo? No início, estimulou a oferta de incentivos e subsídios como meios de atrair as montadoras após o Novo Regime Automotivo. Depois, o governo federal tolerou e mesmo aprovou esse tipo de prática. E quando, finalmente, a guerra fiscal ameaçou sair do controle (cf. caso da Ford/Bahia), o governo federal negligenciou em criar as instituições adequadas que poderiam ter evitado o desenvolvimento de formas mais perversas de competição territorial, a 
começar pela intensificação de negociações e determinação de referências para a negociação entre Estados e montadoras.

A guerra fiscal no setor automobilístico brasileiro é um salto no escuro. A abertura parcial e mesclada da economia, a fragilidade do governo central no balizamento e no controle dos processos de modernização industrial e o despreparo dos governos estaduais e municipais têm contribuído para amplificar os efeitos mais nocivos da globalização. Efeitos que podem até impulsionar o crescimento econômico a curto prazo e geograficamente localizado, mas que, a médio e longo prazo, certamente gerarão mais dependência e instabilidade. E, provavelmente, mais desigualdade.

Porém, há sinais de estímulo emitidos pela sociedade civil contra esse tipo de disputa. O resultado das eleições de 1998 expressou mudanças importantes. Muitos governadores que disputaram agressivamente os investimentos estrangeiros perderam para seus rivais. A guerra fiscal permeou a discussão sobre reforma tributária e fiscal, ainda que de modo não completamente efetivo.

O problema de fundo continua sendo a precariedade institucional voltada para o desenvolvimento. A dificuldade de Estados e prefeituras para estabelecer relações de reciprocidade com as grandes empresas e a sua incapacidade de definir direitos e deveres de modo equilibrado, recoloca com bastante intensidade o debate sobre a profunda disfunção do processo político-institucional brasileiro.

A guerra fiscal apenas amplifica essa disfunção, pois se alimenta da indefinição dos novos papéis atribuídos aos governos subnacionais na elaboração e na implementação de políticas de desenvolvimento que estiveram concentradas no governo federal desde os anos de 1930. E sem o provimento de instituições capazes de irrigar o diálogo com a sociedade civil e os distintos grupos de interesse privados, de modo a regular, estabilizar e legitimar novos comportamentos, no dizer de Polanyi, a guerra fiscal assume, preponderantemente, um caráter autofágico.

\section{NOTAS}

1 O Novo Regime Automotivo, editado em 1995, estabeleceu uma série de vantagens baseadas na diferenciação entre empresas com fábricas instaladas no Brasil e as demais empresas. Para as primeiras, alíquotas de importação substantivamente menores para veículos completos ( $50 \%$ menor). Máquinas e ferramentas teriam alíquotas zero. Autopeças poderiam ser importadas com alíquota inicial de apenas 2\%. O NRA obteve êxito na atracão de novas fábricas. Ao mesmo tempo, apresentava desequilíbrios, beneficiando mais as montadoras e expondo à competição o setor de autopeças. Ignorou a questão trabalho, assim como as referentes à tecnologia, à recapacitação e outras. Foi a primeira peça de política industrial significativa elaborada após a interrupção das atividades da Câmara Setorial da Indústria Automobilística, arranjo tripartite (de curta existência, mas bem-sucedido), voltado para a elaboração de políticas industriais para o setor. Para uma análise mais detalhada dessa experiência ver: Cardoso e Comin, 1993; Arbix, 1996; Arbix e Zilbovicius, 1997.

2 As avaliações da capacidade instalada indicam um salto de 2,4 milhões de unidades/ano para cerca de 3,2 milhões/ano de 1996 a 2001. Cf. Anfavea, 2000, Panorama Setorial.

3 Em 1997, um metalúrgico em São Bernardo (SP) recebia em torno de US\$ 14 por hora de trabalho. Os custos fora de São Paulo eram cerca de 40\% mais baixos, como nas previsões da GM para sua nova fábrica em Gravataí.

4 Em 1996 a relação habitante-por-veículo era de 9,6 no Brasil e 5,8 na Argentina (Anfavea, 1998).

5 Entre 1993 e 1997 a produção de veículos foi a que apresentou maior crescimento relativo no mundo, saltando de um total de 1.070 mil autoveículos no ano de 1992, para 2.070 mil em 1997. No mesmo período, o mercado doméstico saltou de $760 \mathrm{mil}$ para 1.840 mil autoveículos (Anfavea, 2000).

6 Na maioria dos acordos, o crédito fornecido às empresas é sempre pago em moeda local, enquanto o débito do Estado tende a ser garantido em dólar.

7 Protocolo do Estado do Paraná com a Renault, 1996.

8 Protocolo assinado entre a GM e o Estado do Rio Grande do sul, 1997.

9 Protocolo assinado pela Ford e o Estado do Rio Grande do Sul (1997) e que seria posteriormente rompido com a mudança da montadora para Camaçari, na Bahia, em 1999 (ver mais adiante).

10 Entrevista com executivos da GM concedidas ao autor, 2000. 
11 O Regime Automotivo do Norte, Nordeste e CentroOeste, editado em 1996, havia sido criado para atender reivindicações das bancadas regionais de deputados, que exigiam instrumentos federais para atrair novas empresas. Apesar de atrativos vários, nenhuma montadora havia se arvorado a construir uma fábrica nas regiões beneficiadas por incentivos da Sudene.

12 Chega a oito o número de impostos federais sujeitos a renúncia para efeitos de desenvolvimento, de acordo com os programas da Sudene. A aprovação pelo Congresso em regime de urgência do Novo Regime Automotriz, de modo a permitir a ida da Ford para Camaçari (Bahia), autorizou uma renúncia da ordem de cerca R $\$ 700$ milhões/ano, ou um total de US\$ 3,5 bilhões no período de dez anos, com o dólar da época. Depois de árdua polêmica, o Ministério da Fazenda negociou esse valor, reduzindo os impostos a um indicador que forneceu a quantia de R\$ 180 milhões/ano.

13 Durante a polêmica sobre a saída da Ford, no primeiro semestre de 1999, o governo do Rio Grande do Sul divulgou documento afirmando que as perdas de ICMS com a Ford atingiriam a cifra de R\$ 3 bilhões ao longo do tempo.

\section{BIBLIOGRAFIA}

AMSDEN, A. (2001), The rise of the rest: late industrialization outside the North Atlantic Region. Oxford, Oxford University Press.

ANFAVEA. (1998), Anuário Estatístico da Indústria Automobilística Brasileira. São Paulo.

ANFAVEA. (2000), Anuário Estatístico da Indústria Automobilística Brasileira. São Paulo.

ARBIX, G. (1996), Uma aposta no futuro: os primeiros nos da câmara setorial da indústria automobilistica. São Paulo, Scritta.

ARBIX, G. \& ZILBOVICIUS, M. (eds.) (1997), De $J K$ a FHC. A reinvenção dos carros. São Paulo, Scritta.

BRITTAN, L. (1995), "Investment liberalisation: the next great boost to the world economy". Transnational Corporations, 4.

BUDD, L. (1998), "Territorial competition and globalization: Scylla and charybdis of European cities". Urban Studies, 35: 663-685.
CHANG, Há-Joon. (1998), "Globalization, transnational corporations, and economic development: can the developing countries pursue strategic industrial policy in a globalizing world economy?", in D. Baker, G. Epstein e R. Pollin (eds.), Globalization and progressive economic policy, Nova York, Cambridge University Press.

CHESHIRE, P. C. \& GORDON, I. R. (1996), "Territorial competition and the predictability of collective (in)action". International Journal of Urban and Regional Research, 20: 383-400.

(1998), "Territorial competition: some lessons for policy". Annals of Regional Science, 33: 321-346.

COE, D. T. \& Helpman, E. (1995), "International R\&D spillovers". European Economic Review, 39: 859-887.

COE, D. T., HELPMAN, E. \& HOFFMEISTER, A. W. (1997), "North-South R\&D spillovers". Economic Journal, 107: 134-149.

COX, K. \& MAIR, A. (1988), "Locality and community in the politics of local economic development". Annals of the Association of American Geographers, 78: 307-325.

CARDOSO, A. (2000), Trabalhar, verbo transitivo: destinos profissionais dos deserdados da indústria automobilística. Rio de Janeiro, Fundação Getulio Vargas Editora.

CARDOSO, A. \& COMIN, A. (1993), "Câmaras setoriais, modernização produtiva e democratização nas relações de trabalho no Brasil: a experiência do setor automobilístico". Trabalho apresentado no I Congresso Latinoamericano de Sociologia del Trabajo, México.

DIEESE. (1999), Indicadores: emprego e salários. Santo André/São Bernardo/São Caetano.

DONAHUE, J. D. (1997), Disunited states: what's at stake as Washington fades and the states take the lead. Nova York, Basic Books 
DUNNING, J. (1998), "An overview of relations with national governments". New Political Economy, 3 (2): 280-284.

DURANTON, G. (1999), "Trade, wage inequalities and disparities between countries". Growth and Change, 30: 455-478.

EDWARDS, S. (1998), "Openness, productivity and growth: What do we really know?". Economic Journal, 108: 383-398, mar.

FIERGS. (1996), General Motors no Rio Grande do Sul. Estimativa do impacto sobre o emprego. Porto Alegre.

FRANCO, Gustavo. (1996), "A inserção externa e o desenvolvimento", mimeo.

FRENKEL, J. \& Romer, David. (1999), "Does trade cause growth?". American Economic Review, pp. 379-399, jun.

GOVERNO do Paraná. (1995), Programa Paraná mais empregos. Curitiba.

GOVERNO do Rio Grande do Sul. (1997), Documento Interno. Porto Alegre, Secretaria do Desenvolvimento e dos Assuntos Internacionais.

GROSSMAN, G. \& HELPMAN, E. (1991), Innovation and growth in the global economy. Cambridge, MIT Press.

HABERMAS, J. (1971), "The scientization of politics and public opinion", in J. Habermas, Toward a rational society, Londres, Heinemann Educational Books.

JULIUS, D. (1990), Global companies and public policy, Londres, Pinter.

KEATING, M. (1998), The new regionalism in Western Europe: territorial restructuring and political change. Northampton (Mass.), Edward Elgar.

LALL, S. (ed.) (1993), Transnational corporations and economic development. Londres, Routledge.

(1994), "The East Asian Miracle' study: does the bell toll for industrial strategy". World Development, 22 (4): 645-654.
LEVINE，R. \& RENELT, D. (1992), "A sensitivity analysis of cross-country growth regressions". American Economic Review, 82: 942-963.

MARKUSEN, A. (1996), "Interaction between regional and industrial policies: evidence from four countries. International Regional Science Review, 19: 49-77.

MORTIMORE, M. (2000), " Corporate strategies for FDI in the context of Latin America's new economic model". World Development, 28 (9): 1611-1626.

NARULA, R. \& DUNNING, J. (2000), "Industrial development, globalization and multinational enterprises: new realities for developing countries". Oxford Development Studies, 28 (2).

PERRUCCI, R. (1994), Japanese auto transplants in the Heartland. Nova York, Aldine de Gruyter.

POSTHUMA, A. C. (1997), "Autopeças na encruzilhada: modernização desarticulada e desnacionalização", in G. Arbix \& M. Zilbovicius (orgs.), De JK a FHC. A Reinvenção dos Carros, São Paulo, Scritta.

PROTOCOLO de intenções que entre si celebram o Estado do Rio Grande do Sul e a Ford Brasil Ltda. para implantação do complexo industrial Ford (1997).

PROTOCOLO: Termo de compromisso entre o Estado do Rio Grande do Sul e a General Motors do Brasil Ltda (1997).

PROTOCOLO de Acordo entre o Estado do Paraná e a Renault (1996).

RODRIGUEZ, F. \& RODRIK, D. (2000), "Trade policy and economic growth: a skeptic's guide to the cross-national literature". Cambridge, NBER papers.

RODRÍGUEZ-Pose, A. (1998), Dynamics of regional growth in Europe: social and political factors. Oxford, Clarendon Press.

RODRÍGUEZ-Pose, A. \& TOMANEY, J. (1999), "Industrial crisis in the centre of the peri- 
phery: stabilisation, economic restructuring and policy responses in the São Paulo metropolitan region". Urban Studies, 36: 479-498.

RODRÍGUEZ-Pose, A. \& Arbix, G. (2001), "Strategies of Waste: bidding wars in the Brazilian automobile sector". International Journal of Urban and Regional Research, 25 (1): 134-154.

SACHS, J. \& Warner, A. (1995), "Economic reform and the process of global integration". Brookings Papers on Economic Activity, 1: 1-95.

(1997), "Fundamental sources of longrun growth". American Economic Review, 87: 184-188.

STORPER, M. (1991), Industrialization, economic development, and the regional question in the Third World. Londres, Pion.

STOPFORD, J. (1994), "The growing interdependence between transnational corporations and governments". Transnational Corporations, 3 .

THOMAS, K. (1997), Capital beyond borders. States and firms in the auto industry, 196094. Nova York, St. Martin's Press Inc.

UNCTAD. (1996), "Explaining and forecasting regional flows of FDI", Nova York, CTC 26. UN.

VEIGA, J. P. C. (1999), As políticas domésticas e a negociação internacional: o caso da indústria automobilística no Mercosul. Tese de doutorado, Sao Paulo, FFLCH, USP.

VERNON, R. (1998), In the burricane's eye: the troubled prospects of multinational enterprises. Cambridge, Harvard University Press.

WADE, R. (1990), Governing the market. Princeton, Princeton University Press.

WILLIAMSON, J. G. (1997), "Globalization and inequality, past and present". World Bank Research Observer, 12: 117-135.
WOOD, A. (1994), North-South trade, employment and inequality: changing fortunes in a skill driven world. Oxford, Clarendon Press.

WOO, Jun-en. (1991), Race to the Swift: State and finance in Korean industrialization. Nova York, Columbia University Press. 


\section{POLÍTICAS DO DESPERDÍCIO E ASSIMETRIA ENTRE PÚBLICO E PRIVADO NA INDÚSTRIA UTOMOBILÍSTICA BRASILEIRA}

\section{Glauco Arbix}

\section{Palavras-chave}

Guerra fiscal; Indústria automobilística; Políticas públicas; Política industrial; Desenvolvimento regional.

Nos anos de 1990, a disputa entre Estados e municípios por novos investimentos no setor automotivo atingiu grande intensidade. Poucos Estados resistiram à tentação de oferecer vultuosos incentivos às montadoras esperando recompensa na forma de empregos, tecnologia e aumento de impostos. A competição ganhou o nome de guerra fiscal, por estar baseada no jogo com a receita e a arrecadação futura do ICMS. Ao longo do tempo, os mecanismos utilizados para atrair novos investimentos foram se tornando mais sofisticados e dificilmente serão completamente extintos por uma eventual reforma fiscal sem que a relação entre os Estados seja reconfigurada politicamente. Exatamente por isso, a questão de fundo atualizada pela guerra fiscal possui uma dimensão nacional que toca nos alicerces de nossa sociedade ao sugerir a busca de um novo equilíbrio entre cooperação e conflito na Federação brasileira. Nossa hipótese central é que essa disputa, no formato atual, representa grande desperdício de recursos públicos, tanto para os governos estaduais quanto para o país como um todo. As regras do jogo, as armas e o território da guerra fiscal favorecem, em primeira instância, as grandes montadoras que, de fato, comandam as negociações.

\section{POLICIES OF WASTE AND DESIQUILIBRIUM BETWEEN THE PUBLIC AND THE PRIVATE SPHERES IN THE BRAZILIAN AUTOMOBILE INDUSTRY}

Glauco Arbix

\section{Keywords}

Fiscal war; Automobile industry; Public policy; Industrial policy; Regional development.

In the 1990s, the dispute between states and municipalities for new investments in the automobile industry increased in terms of frequency and intensity. Few states could resist the temptation to offer enormous incentives to car manufacturers with the hope of gaining jobs, technology and more taxes in exchange. The competition was baptized the "fiscal war" because the game was based basically on revenue and future tax collection of the ICMS, a kind of value-added tax collected by the Brazilian states. As time went by, the mechanisms used to attract new investments were becoming increasingly sophisticated and more difficult to abolish by an eventual tax reform at the national level. The current question at the bottom of the fiscal war has both a national and political dimension. In fact, it touches upon the bases of our society by revealing the need to find a new equilibrium between cooperation and conflict among Brazil's federation of states. Our central hypothesis is that this dispute, in its actual form, represents an enormous waste of public resources for state governments and the country as a whole. The rules of the game, the weapons involved, and the territory of the fiscal war favors, in the first instance, the large car makers.

\section{POLITIQUES DE GASPILLAGE ET DÉSÉQUILIBRE ENTRE LE SECTEUR PUBLIC ET LE SECTEUR PRIVÉ DANS L'INDUS- TRIE AUTOMOBILE BRÉSILIENNE}

Glauco Arbix

\section{Mots-clés}

Guerre fiscale; Industrie automobile; Politiques publiques; Politique industrielle; Développement régional.

Au cours des années 1990, l'affrontement entre les États Fédérés et les communes pour de nouveaux investissements dans le secteur automobile s'est beaucoup intensifiée. Peu d'États ont résisté à la tentation d'offrir d'importantes subventions aux entreprises du secteur automobile en y espérant une récompense sous la forme d'emplois, de technologie et d'augmentation des impôts. La compétition a été baptisée de guerre fiscale, car elle s'est fondée sur le jeu entre la recette et la future perception de l'Impôt sur la Circulation des Marchandises et des Services/ICMS. Au cours des années, les mécanismes employés pour attirer de nouveaux investissements sont devenus de plus en plus sophistiqués et seront difficilement supprimés par une éventuelle réforme fiscale sans que la relation entre les États ne soit politiquement remodelée. C'est exactement pour ça que la question de fond, rendue actuelle par la guerre fiscale revêt une dimension nationale qui touche les bases de notre société en suggérant la recherche d'un nouvel équilibre entre coopération et conflit dans la fédération brésilienne. Notre hypothèse centrale est que cette dispute, telle qu'elle se présente, correspond à un grand gâchis de ressources publiques, aussi bien pour les gouvernements des États que pour le pays en tant que tel. Les règles du jeu, les armes et le territoire de la guerre fiscale bénéficient, en premier lieu, les grandes entreprises automobiles qui, en réalité, mènent les négociations. 